\title{
Co-expression of human malaria parasite Plasmodium falciparum orotate phosphoribosyltransferase and orotidine 5'-monophosphate decarboxylase as enzyme complex in Escherichia coli: a novel strategy for drug development
}

Panan Kanchanaphum, Jerapan Krungkrai

Department of Biochemistry, Faculty of Medicine, Chulalongkorn University, Bangkok 10330, Thailand

\begin{abstract}
Background: Human malaria parasite Plasmodium falciparum operates de novo pyrimidine biosynthetic pathway. The fifth and sixth enzymes of the pathway form a heterotetrameric complex, containing two molecules each of orotate phosphoribosyltransferase (OPRT) and orotidine 5'-monophosphate decarboxylase (OMPDC).

Objective: Define the function of OPRT-OMPDC enzyme complex of P. falciparum by co-expressing the enzymes in Escherichia coli.

Methods: The constructed plasmids containing either P. falciparum OPRT or OMPDC were cloned in E. coli by co-transformation. Both genes were co-expressed as OPRT-OMPDC enzyme complex and the complex was purified by chromatographic techniques, including $\mathrm{N}^{2+}$-NTA affinity, Hi Trap Q HP anion-exchange, uridine 5'monophosphate affinity, and Superose 12 gel-filtration columns. Physical and kinetic properties of the enzyme complex were analyzed for its molecular mass.

Results: Co-transformation of PfOPRT and PfOMPDC plasmids in E. coli were achieved with a clone containing DNA ratio of 1:2, respectively. Both plasmids remained stable and were functionally expressed in the $E$. coli cell for at least 20 weeks. The P. falciparum OPRT-OMPDC enzyme complex were co-expressed and the complex was co-eluted in all chromatographic columns during purification and physical analysis. The molecular mass of the complex was $130 \mathrm{kDa}$, whereas the PfOPRT and PfOMPDC component were 35.6 and $41.5 \mathrm{kDa}$, respectively. The enzymatic activities of the complex were competitively inhibited by their products of each enzyme component.

Conclusion: P. falciparum OPRT and OMPDC in E. coli as an enzyme complex were co-transformed and functionally co-expressed. These have similar properties to the native enzyme purified directly from $P$. falciparum, and this character is different from that of the human host organism. The enzyme complex would be suitable as new target to research selective inhibitors as suitable drugs to better control this disease.
\end{abstract}

Keywords: Co-expression, co-transformation, enzyme complex, orotate phosphoribosyltransferase (OPRT), orotidine 5'-monophosphate decarboxylase (OMPDC), Plasmodium falciparum

Malaria (Plasmodium falciparum) afflicts approximately 2.5 million people worldwide [1]. The majority of deaths occur in children thus making it a major cause of human suffering. Young people in the
sub-Saharan region of Africa are mostly at risk due to their lack of naturally acquired immunity to the malaria species that infect human [2]. 
Severe disease caused by $P$. falciparum encompasses a range of presentations including severe anemia, cerebral malaria, hypoglycemia and a systemic syndrome analogous to toxic shock $[3,4]$. Nowadays, malaria chemotherapy is disturbed by the parasite resisting to many drugs such as artemisinin $[5,6]$, quinoline derivative chloroquine, and the folate antagonist pyrimethamine [7]. More efficacious drugs specific to malaria parasite are urgently required. Therefore, attempts have been done to find the new drug or new drug target to conquer this disease. Enzymes of de novo pyrimidine biosynthesis pathway in the malaria parasite are the potential candidate for new drug target $[8,9]$.

There are six enzymatic reaction steps in the de novo pyrimidine pathway. The important enzymes that may be the good drug targets are identified in the last two steps of the pathway [9]. In the final two steps, uridine 5'-monophosphate (UMP) synthesis requires the addition of ribose phosphate moiety from 5'-phosphoribosyl-1-pyrophosphate (PRPP) to become orotate. Then, the orotate phosphoribosyltransferase (EC 2.4.2.10, OPRT) would form orotidine 5'-monophosphate (OMP) and pyrophosphate (PPi). Thereafter, decarboxylation of OMP would be done to UMP by OMP decarboxylase (EC 4.1.1.23, OMPDC).

The OPRT and OMPDC, enzymes almost prokaryotes and yeast $[10,11]$, are encoded by two separate genes. On the other hand, in most multicelullar eukaryotes, the genes for both enzymes are fused into single gene, namely UMP synthase, which has two different catalytic domains [12-14]. In $P$. falciparum, the OPRT and OMPDC genes are located on chromosome 5 and 10, respectively [15]. The open reading frames, containing one exon of both genes, encode proteins with 281 amino acids for PfOPRT and 323 amino acids for PfOMPDC $[16,17]$. Both enzymes are found to be an enzyme complex, containing two molecules each of PfOPRT and PfOMPDC [17]. The PfOPRT-PfOMPDC enzyme complex is uniquely found in $P$. falciparum $[9,16,17]$.

In this study, we cloned E. coli harboring two different constructed plasmids, and expressed both genes simultaneously. We showed that the expressed PfOPRT and PfOMPDC form an enzyme complex in all chromatographic columns. Physical and kinetic properties of the enzyme complex were characterized, thus, comparing to its monofunctional enzyme.

\section{Materials and methods Materials}

Restriction enzymes and chemical reagents were purchased from Promega (Madison, USA) and Sigma (St Louis, USA). There were of highest quality commercially available. Nickel-nitrotriacetic acid $\left(\mathrm{Ni}^{2+}\right.$-NTA) agarose affinity gel was obtained from Qiagen (Hamburg, Germany). Hi Trap Q HP anionexchange was from GE Healthcare (UK). Fast protein liquid chromatographic (FPLC) system with Superose 12 gel-filtration column was from Amersham Biosciences (GE Healthcare, Sweden). UMP-agarose affinity gel was obtained from Sigma. Molecular mass marker for sodium dodecyl sulfate polyacrylamide gel electrophoresis (SDS-PAGE) and protein assay were purchased from BioRad (Hercules, USA). The $1 \mathrm{~Kb}$ DNA ladder was from Vivantis. PfOPRT and PfOMPDC were cloned and expressed by using pQE30Xa (Qiagen Humburg, Germany) and pTrcHisA plasmid vectors (Invitrogen, Carlsbud, USA) [17].

\section{Competent $E$. coli cell preparation}

An $E$. coli TOP10 colony from a culture LuriaBertani (LB) plate was picked and incubated in LB broth at $37^{\circ} \mathrm{C}$ for overnight. It was transferred into $100 \mathrm{~mL} \mathrm{LB}$ broth, and incubated at $37^{\circ} \mathrm{C}$ until $\mathrm{OD}_{600}$ of the culture was 0.4 . The culture was centrifuged at $3,000 \mathrm{~g}$ for 10 minutes at $4^{\circ} \mathrm{C}$. The supernatant was discarded. The cell pellet was suspended in $10 \mathrm{~mL}$ of iced-cold $0.1 \mathrm{M} \mathrm{CaCl}_{2}$, and left on ice for 30 minutes. The cell was centrifuged at $3,000 \mathrm{~g}$ for 10 minutes at $4^{\circ} \mathrm{C}$. The cell pellet was resuspended again in $5 \mathrm{~mL}$ of cold $0.1 \mathrm{M} \mathrm{CaCl}_{2}$ and cooled on ice for another 15 minutes. The cell was then centrifuged at 3,000 $\mathrm{g}$ for 10 minutes at $4^{\circ} \mathrm{C}$. The cell pellet was suspended in $1 \mathrm{~mL}$ cold $0.1 \mathrm{M} \mathrm{CaCl}_{2}$ and $1 \mathrm{~mL}$ of glycerol by gentle vortexing.

\section{Co-transformation of PFOPRT and PFOMPDC}

Five ng of each of PfOPRT-pQE30Xa and PfOMPDC-pTrcHisA were added into $20 \mu \mathrm{L}$ of the competent cell, and left on ice for 20 minutes. The mixture was shocked at $42^{\circ} \mathrm{C}$ for one minute, and cooled on ice for two minutes. The cell was added with $250 \mu \mathrm{L}$ SOC media and left for one hour and spread on LB plate containing with $100 \mu \mathrm{g} / \mathrm{mL}$ of ampicillin. The plate was incubated overnight at $37^{\circ} \mathrm{C}$. 


\section{Plasmid stability test}

The positive clone having both PfOPRT-pQE30Xa and PfOMPDC-pTrcHisA plasmids stored at $4^{\circ} \mathrm{C}$. The clones were cultured overnight at $37^{\circ} \mathrm{C}$. The plasmids were analyzed and the cells were expressed for both recombinant enzymes.

\section{Recombinant protein expression and purification}

The competent $E$. coli TOP 10 cells were transformed with PfOPRT-pQE30Xa and PfOM PDC-pTrcHisA plasmids. The cells were grown in $\mathrm{LB}$ medium at $37^{\circ} \mathrm{C}$ until $\mathrm{OD}_{600}$ of the culture was 0.5 , and then induced with $1 \mathrm{mM}$ isopropyl $\beta$-Dthiogalactopyranoside, for 18 hours at $18^{\circ} \mathrm{C}$ using a refrigerated incubating shaker (Kuhner), and harvested by centrifugation at $8,000 \mathrm{~g}$. Then, it was washed twice with cold $1 \mathrm{X}$ phosphate buffer saline and stored as a cell paste by freezing at $-70^{\circ} \mathrm{C}$ until use.

Frozen cell paste was suspended in a lysis buffer [18]. One tablet of protease inhibitor cocktail (Roche) was added to the lysis buffer. Lysozyme and triton $\mathrm{X}-100$ were added to final concentrations of $0.1 \%$. The mixture was sonicated within ultrasonic Sonoplus homogenizer (Bandelin, Berlin, Germany). The E. coli lysate was centrifuged at $18,000 \mathrm{~g}$ at $4^{\circ} \mathrm{C}$ for 30 minutes. The supernatant fluid was loaded onto a 700 $\mu \mathrm{L}$ of $\mathrm{Ni}^{2+}$-NTA agarose affinity column (bed volume $=350 \mu \mathrm{l}$ ) equilibrated with buffer $\mathrm{A}[18]$. The column was washed twice with $5 \mathrm{ml}$ of buffer B [18], and eluted with $3 \mathrm{~mL}$ buffer $\mathrm{C}[18]$. The eluent from $\mathrm{Ni}^{2+}$ NTA agarose affinity column was added onto Hi Trap Q HP anion-exchange column, which had been equilibrated with $50 \mathrm{mM}$ Tris- $\mathrm{HCl} \mathrm{pH} 8.0$ and eluted with $50 \mathrm{mM}$ Tris- $\mathrm{HCl}$ containing $250 \mathrm{mM} \mathrm{NaCl}$.

The eluent containing both OPRT and OMPDC activities from Hi Trap QHP column were pooled, and applied to Superose 12 gel-filtration FPLC column, which was equilibrated with $50 \mathrm{mM}$ Tris- $\mathrm{HCl} \mathrm{pH} 8.0$ containing $250 \mathrm{mM} \mathrm{NaCl}$. The enzyme was eluted with this buffer for 45 minutes at flow rate of $0.5 \mathrm{~mL} /$ $\mathrm{min}$, the $0.5-\mathrm{mL}$ fractions were collected and assayed for both OPRT and OMPDC activities. The Superose 12 FPLC column was calibrated with molecular mass markers, thyroglobulin $(670 \mathrm{kDa})$, immunoglobulin (158 $\mathrm{kDa})$, bovine serum albumin ( $66 \mathrm{kDa})$, ovalbumin (44 $\mathrm{kDa})$, myoglobin $(17 \mathrm{kDa})$, and vitamin B12 (1.35 $\mathrm{kDa})$. The pooled eluent from Hi Trap Q column was loaded onto UMP-agarose affinity column with a bed volume of $1 \mathrm{ml}$. The column was washed with $1 \mathrm{~mL}$
$50 \mathrm{mM}$ Tris- $\mathrm{HCl} \mathrm{pH} 8.0$ containing $250 \mathrm{mM} \mathrm{NaCl}$ for five times. The enzyme was eluted with $5 \mathrm{~mL} 50 \mathrm{mM}$ Tris- $\mathrm{HCl} \mathrm{pH}$ 8.0, $250 \mathrm{mM} \mathrm{NaCl}$, containing $0.5 \mathrm{mM}$ UMP. The $0.5-\mathrm{mL}$ per fractions were collected and assayed for both OPRT and OMPDC activities.

\section{Monofunctional PfOPRT and PFOMPDC enzyme preparation}

The monofunctional form of PfOPRT and PfOMPDC were prepared as described before [17].

\section{Protein assay}

Protein concentrations were determined by Bradford method [19] using bovine serum albumin as standard.

\section{Enzyme activity measurement}

A spectrophotometric method was used to detect forward reaction of OPRT and OMPDC activity by measuring the decreasing concentrations of orotate and OMP [17, 20, 21]. The assay was performed in quartz cuvettes with a UV-visible Shimadzu spectrophotometer (model UV1601, Kyoto, Japan) equipped with a temperature controlled cuvette holder.

\section{Inhibitory effect of pyrimidines}

The inhibitory study in PfOPRT-PfOMPDC enzyme complex were determined by using the pure enzyme complex after anion-exchange chromatography ( $>95 \%$ pure as observed by SDSPAGE). Kinetic data of the initial velocity and inhibitions were fitted to two equations (Equations 1 and 2) for competitive and non-competitive inhibitors, respectively, by using the Cleland computational method as follows [22].

$$
\begin{aligned}
& \mathrm{v}=\frac{\mathrm{V}_{\text {max }}[\mathrm{S}]}{[\mathrm{S}]+\mathrm{K}_{\mathrm{m}}^{\text {app }}\left(1+[\mathrm{I}] / \mathrm{K}_{\mathrm{i}}\right)}, \\
& \mathrm{v}=\frac{\mathrm{V}_{\text {max }}[\mathrm{S}]}{\left([\mathrm{S}]+\mathrm{K}_{\mathrm{m}}^{\text {app }}\right)\left(1+[\mathrm{I}] / \mathrm{K}_{\mathrm{i}}\right)} .
\end{aligned}
$$

In the above, $\mathrm{v}$ denotes initial velocity, $\mathrm{V}_{\text {max }}$ denotes maximum velocity, [S] denotes concentration of substrate, $[\mathrm{I}]$ denotes concentration of inhibitor, $\mathrm{K}_{\mathrm{m}}$ app denotes Michaelis constant in the presence of inhibitor, and $\mathrm{K}_{\mathrm{i}}$, inhibitory constant. 


\section{Results}

Co-transformation, co-expression, and plasmid stability of PFOPRT and PFOMPDC

PfOPRT-pQE30Xa and PfOMPDC-pTrcHisA were co-transformed into $E$. coli TOP10 cell. The fifty-six clones grown into LB plate with $100 \mu \mathrm{g} / \mathrm{mL}$ of ampicillin were collected for plasmid analysis. There were only four positive clones that contained both PfOPRT-pQE30Xa and PfOMPDC-pTrcHisA plasmids. The DNA size of PfOPRT-pQE30Xa and PfOMPDC-pTrcHisA plasmids were 4.3 and $5.4 \mathrm{~Kb}$, respectively (Fig. 1).

The DNA ratio between PfOPRT-pQE30Xa and PfOMPDC-pTrcHis A was approximately 1:2. The ratio of protein between PfOPRT and PfOMPDC from SDS-PAGE was about 1:1 (Fig. 2).

For plasmid stability test, the plasmid of positive clone stored at 2, 4, 8, 12, 16, and 20 weeks were analyzed. All the plasmids still contained PfOPRTpQE30Xa and PfOMPDC-pTrcHis A plasmids (Fig. 3). However, the intensity of DNA band of PfOPRTpQE30Xa plasmid at 16 and 20 weeks were weaker than those of 2, 4, 8, and 12 weeks. The DNA band ratio between PfOPRT-pQE30Xa and PfOMPDCpTrcHisA at week 16 and 20 was 1:3. However, the PfOPRT-PfOMPDC enzyme complex from E. coli cell at the various times was consistently expressed at the same level.

\section{PfOPRT-PfOMPDC enzyme complex preparation}

PfOPRT-PfOMPDC enzyme complex was expressed in E. coli TOP10. The enzyme complex was subsequently purified through $\mathrm{Ni}^{2+}$-NTA agarose affinity and Hi Trap Q HP anion-exchange chromatography. The SDS-PAGE of the purified PfOPRT-PfOMPDC enzyme complex was shown in Fig. 2. After Hi Trap QHP anion-exchange chromatography, the enzyme complex was subjected to both Superose 12 gel-filtration FPLC column and UMP-agarose affinity to confirm its complexity. The OPRT and OMPDC activities were found in overlapping peaks after eluting with $50 \mathrm{mM}$ Tris- $\mathrm{HCl}$ pH 8.0 containing $250 \mathrm{mM} \mathrm{NaCl}$ in Superose 12 gelfiltration FPLC column and with $0.5 \mathrm{mM}$ UMP in UMP-agarose affinity column (Fig. 4, 5).

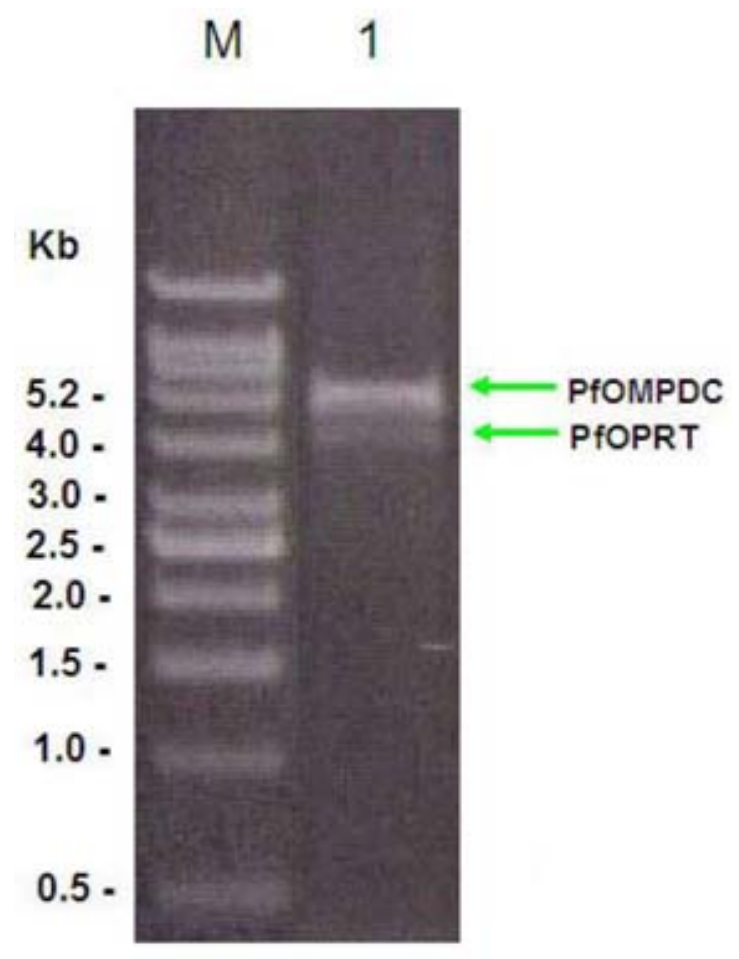

Fig. 1 Agarose gel analysis of PfOPRT-pQE30Xa and PfOMPDC-pTrcHisA plasmids co-transformed in the competent E. coli cell. Lane M, $1 \mathrm{~Kb}$ DNA ladder marker. Lane 1, size of plasmids after Bam HI digestion of PfOPRT-pQE30Xa and PfOMPDC- pTrcHisA plasmids were 4.3 and $5.4 \mathrm{~Kb}$, respectively. The DNA ratio of PfOPRT-pQE30Xa and PfOMPDC-pTrcHisA was about 1:2. 


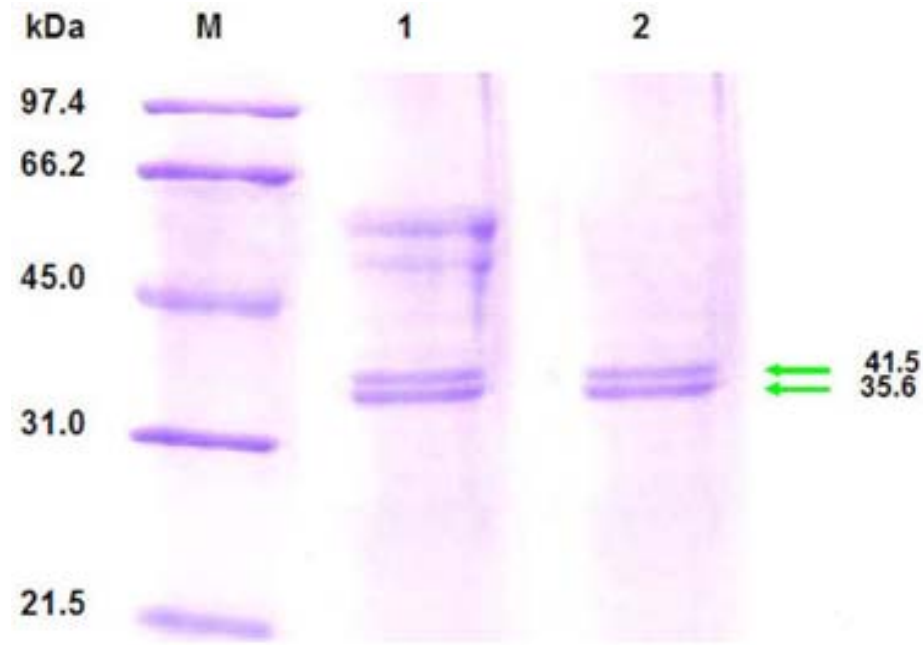

Fig. 2 SDS-PAGE of PfOPRT-PfOMPDC enzyme complex purified by $\mathrm{Ni}^{2+}$-NTA agarose affinity and Hi Trap Q HP anionexchange chromatographic columns. The enzyme complex was subjected to SDS-PAGE on a gradient 8-16\% polyacrylamide gel. Lane M is low range molecular mass markers. Lane 1, the PfOPRT-PfOMPDC enzyme complex purified from $\mathrm{Ni}^{2+}$-NTA agarose affinity column. Lane 2, the enzyme complex purified from Hi Trap Q HP anionexchange column. The enzyme complex showed a homogeneous preparation with the molecular mass of $35.6 \mathrm{kDa}$ for PfOPRT component and $41.5 \mathrm{kDa}$ for PfOMPDC component. The protein ratio of PfOPRT and PfOMPDC purified at the Hi Trap Q HP column was approximately 1:1.

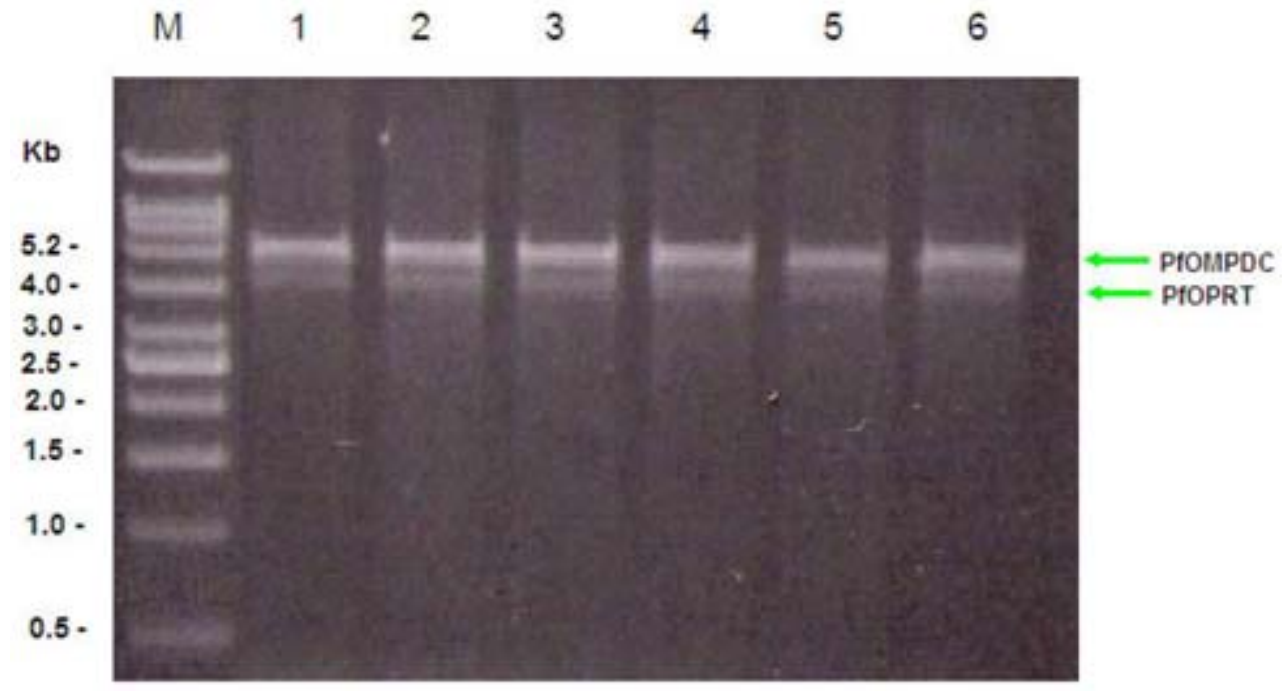

Fig. 3 Agarose gel analysis of PfOPRT-pQE30Xa and PfOMPDC- pTrcHisA plasmids at various times of storage. Lane M, $1 \mathrm{~Kb}$ DNA ladder marker. Lane 1-6, Bam HI digestion of PfOPRT-pQE30Xa and PfOMPDC-pTrcHisA plasmids isolated from $E$. coli clone when stored at 2, 4, 8, 12, 16 and 20 weeks, respectively. Both recombinant plasmids retained at all various times during storage but DNA ratio of PfOPRT-pQE30Xa and PfOMPDC-pTrcHisA plasmids at 16 and 20 weeks after storage was approximately 1:3. 


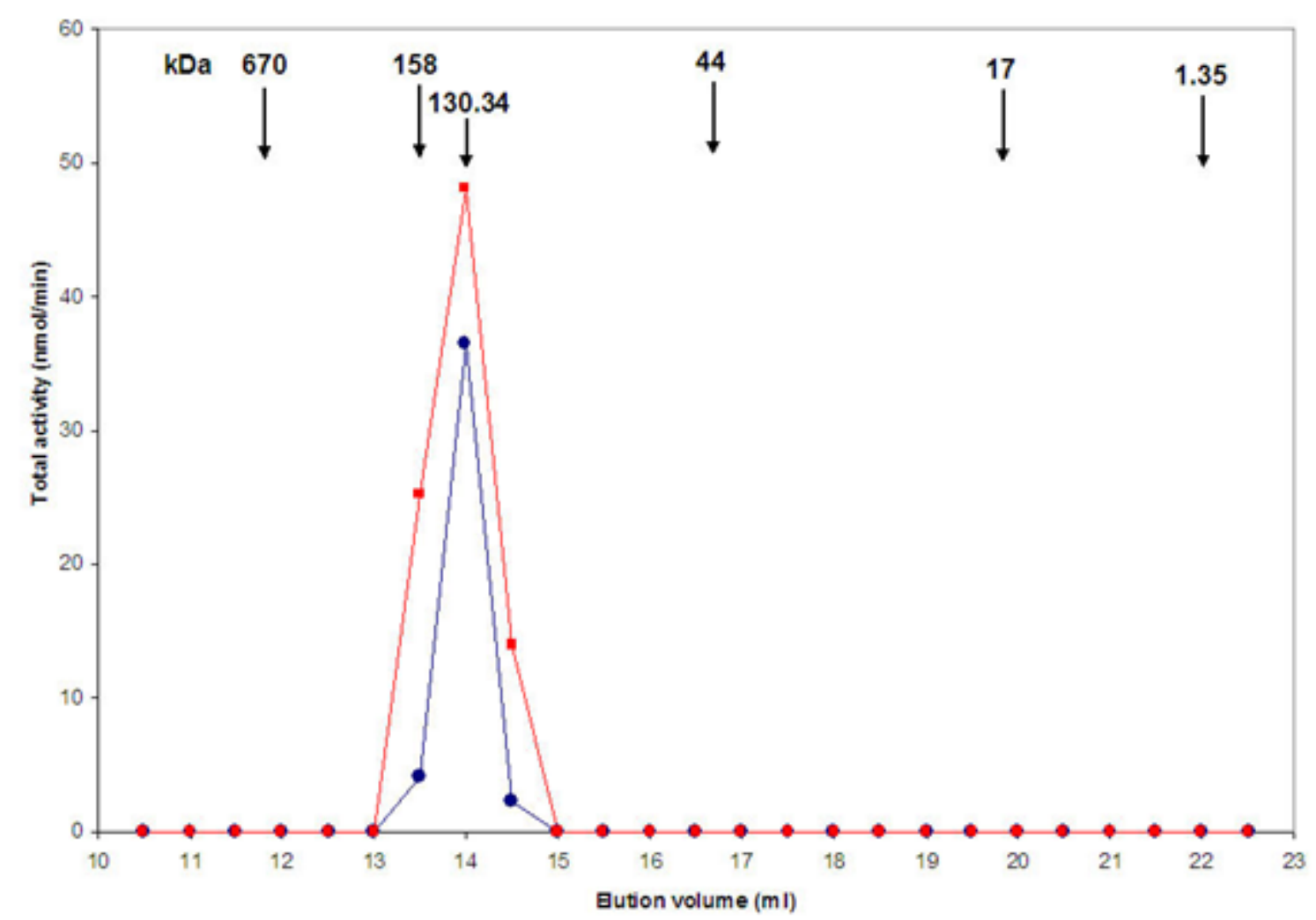

Fig. 4 Chromatographic profile of the purified PfOPRT-PfOMPDC enzyme complex on the Superose 12 gel-filtration FPLC column. The column was equilibrated with $50 \mathrm{mM}$ Tris- $\mathrm{HCl} \mathrm{pH} 8.0$ containing $250 \mathrm{mM} \mathrm{NaCl}$. Fractions $(0.5 \mathrm{~mL})$ were collected and then assayed for the co-eluting enzyme activities ( $\bullet$ for PfOPRT and $\boldsymbol{\square}$ for PfOMPDC). The arrows indicated the position of molecular mass marker ( $\mathrm{kDa})$. The PfOPRT and PfOMPDC were co-eluted symmetrically at elution volume of $14 \mathrm{ml}$. The molecular mass of PfOPRT-PfOMPDC enzyme complex was $130.34 \mathrm{kDa}$, determined from a plot of elution volume against log molecular mass of the markers.

\section{Properties of PfOPRT-PfOMPDC enzyme complex}

The molecular mass by SDS-PAGE of PfOPRT was $35.6 \mathrm{kDa}$ and $41.5 \mathrm{kDa}$ for PfOMPDC (Fig. 2). However, the molecular mass of the active PfOPRTPfOMPDC enzyme complex was found to be 130.34 $\mathrm{kDa}$, as determined from the elution pattern in the Superose 12 gel-filtration FPLC column (Fig. 4). By purifying using Superose 12 gel-filtration FPLC column, the activity of PfOPRT component of enzyme complex at $14 \mathrm{~mL}$ eluting volume was $36.5 \mathrm{nmol} / \mathrm{min}$ and $48.0 \mathrm{nmol} / \mathrm{min}$ of PfOMPDC component (Fig. 4). By UMP-agarose affinity column, the recombinant active enzyme complex had activities of 34.0 and $43.4 \mathrm{nmol} / \mathrm{min}$ for each of the PfOPRT and the PfOMPDC components, respectively (elution volume $=6 \mathrm{~mL}$ ) (Fig. 5). These eluting properties of both enzymes confirmed the in vivo complex formation occurring during enzyme expression in E. coli.

\section{Kinetics and inhibitory effect of pyrimidines}

$\mathrm{K}_{\mathrm{m}}, \mathrm{V}_{\max }$ values of the monofunctional and complex were determined (Table $\mathbf{1}$ and $\mathbf{2}$ ) by varying concentrations of each substrate and measuring initial velocity (v). OMP, one of the product of OPRT reaction, was a good inhibitor in both monofunctional PfOPRT and enzyme complex (Table 1).

The product of OMPDC catalysis, UMP, was slightly inhibited in monofunctional and complex behaving as a weak inhibitor for both enzyme forms (Table 2). Kinetics of OMP and UMP were fitted to Equation 1, suggesting they are competitive inhibitors.

All available pyrimidines and their derivatives including ribose 5-phosphate, which is a bottom part of the substrate and the product of PfOMPDC, were found to have more inhibitory effects for the monofunctional form than for the PfOMPDC component of the enzyme complex (Table 3). The kinetic of ribose 5-phosphate inhibition was fitted to Equation 2. More interestingly, the complex was more sensitive to 5-fluoroototate than to the monofunctional enzyme. 


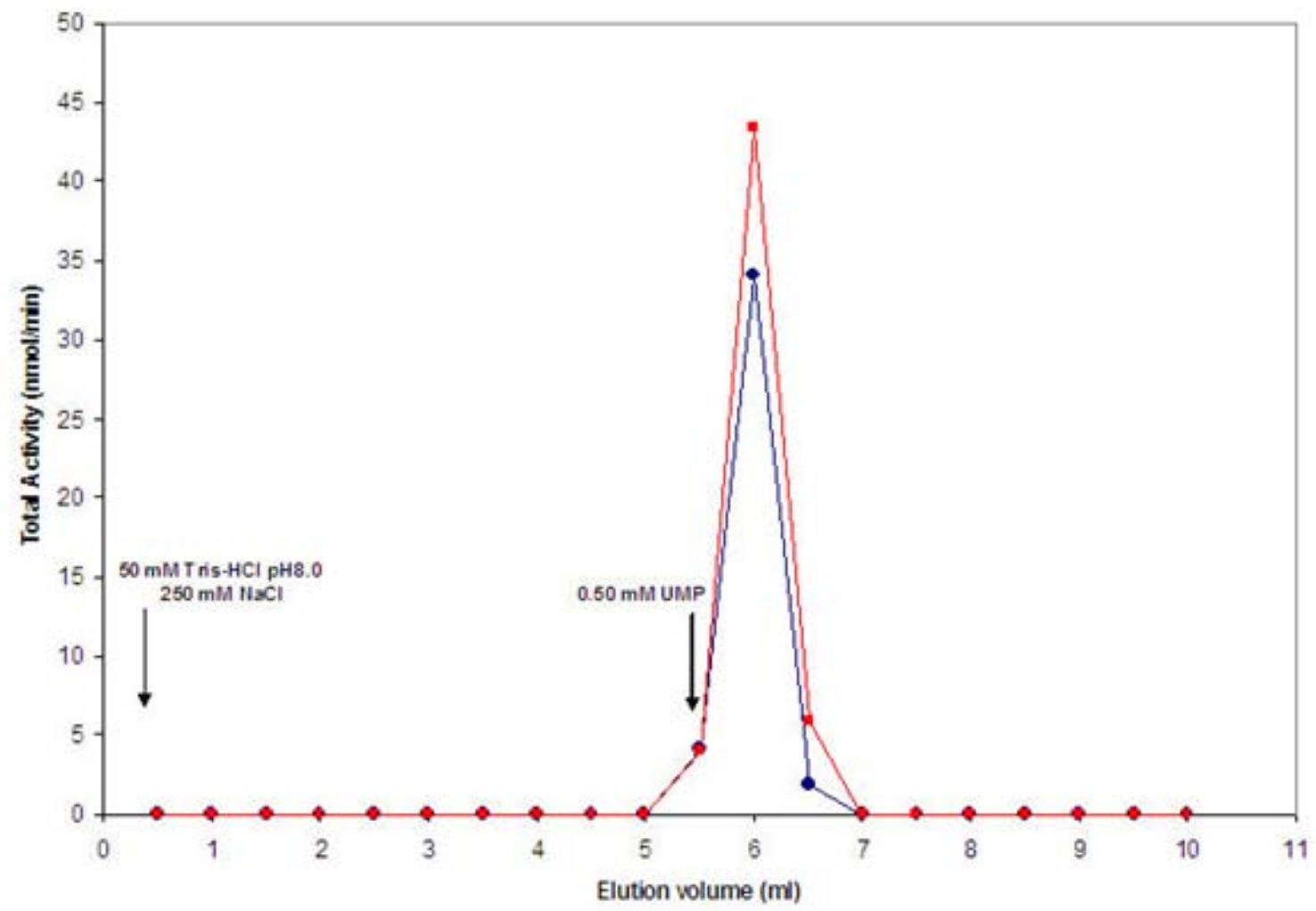

Fig. 5 Chromatographic profile of the purified of PfOPRT-PfOMPDC enzyme complex on the UMP-agarose affinity column. The 1-mL bed volume column was equilibrated with $50 \mathrm{mM}$ Tris- $\mathrm{HCl} \mathrm{pH} 8.0$ containing $250 \mathrm{mM} \mathrm{NaCl}$. The fractions $(0.5 \mathrm{~mL})$ were collected and then assayed for both enzyme activities ( $\bullet$ for PfOPRT and $\square$ for PfOMPDC). The PfOPRT-PfOMPDC was co-eluted symmetrically by the above buffer in the presence of $0.5 \mathrm{mM}$ UMP.

Table 1. Kinetic and inhibitory constants of PfOPRT in the monofunctional form (mono) and in the enzyme complex. The substrate concentrations were varied from $6.25 \mu \mathrm{M}$ to $250 \mu \mathrm{M}$. OMP at $25 \mu \mathrm{M}$ was used for the inhibition study.

\begin{tabular}{lclllcc}
\hline PfOPRT & Inhibitor & Substrate & $\begin{array}{l}\mathbf{V}_{\mathbf{m a x}} \\
(\mathbf{n m o l} / \mathbf{m i n})\end{array}$ & $\begin{array}{l}\mathbf{K}_{\mathbf{m}} \\
(\boldsymbol{\mu} \mathbf{M})\end{array}$ & $\begin{array}{l}\mathbf{K}_{\mathbf{i}} \\
(\boldsymbol{\mu} \mathbf{M})\end{array}$ & $\begin{array}{l}\text { Inhibition } \\
\text { type }\end{array}$ \\
\hline Mono & - & Orotate & 3.4 & 18.2 & - & - \\
Mono & OMP & Orotate & 3.3 & 37.0 & 24.1 & Competitive \\
Mono & - & PRPP & 3.2 & 28.6 & - & - \\
Mono & OMP & PRPP & 3.2 & 28.2 & 15.7 & Competitive \\
Complex & - & Orotate & 3.1 & 7.0 & - & - \\
Complex & OMP & Orotate & 3.0 & 13.1 & 28.9 & Competitive \\
Complex & - & PRPP & 3.3 & 7.9 & - & - \\
Complex & OMP & PRPP & 3.3 & 10.5 & 26.3 & Competitive \\
& & & & & &
\end{tabular}


Table 2. Kinetic and inhibitory constants of PfOMPDC in the monofunctional form (mono) and enzyme complex. The concentration of OMP were varied from $6.25 \mu \mathrm{M}$ to $250 \mu \mathrm{M}$. UMP at $500 \mu \mathrm{M}$ was used for the inhibition study.

\begin{tabular}{lcllcc}
\hline PfOMPDC & Inhibitor & $\begin{array}{l}\text { Vmax } \\
(\mathbf{n m o l} / \mathbf{m i n})\end{array}$ & $\begin{array}{l}\mathbf{K}_{\mathbf{m}} \\
(\boldsymbol{\mu M})\end{array}$ & $\begin{array}{l}\mathbf{K}_{\mathbf{i}} \\
(\boldsymbol{\mu} \mathbf{M})\end{array}$ & $\begin{array}{l}\text { Inhibition } \\
\text { type }\end{array}$ \\
\hline Mono & - & 11.9 & 11.2 & - & - \\
Mono & UMP & 11.9 & 11.2 & $1,376.1$ & Competitive \\
Complex & - & 12.9 & 10.5 & - & - \\
Complex & UMP & 12.9 & 10.5 & $1,697.8$ & Competitive
\end{tabular}

Table 3. Inhibitory constants of pyrimidines and ribose 5-phosphate against PfOMPDC in the monofunctional form (mono) and in the enzyme complex.

\begin{tabular}{llll}
\hline Component $^{*}$ & $\begin{array}{l}\text { Mono } \\
\mathbf{K}(\boldsymbol{\mu} \mathbf{M})\end{array}$ & $\begin{array}{l}\text { Complex } \\
\mathbf{K}_{\mathbf{i}}(\boldsymbol{\mu M} \mathbf{M})\end{array}$ & $\begin{array}{l}\text { Inhibition } \\
\text { type }\end{array}$ \\
\hline Uracil & 534.5 & $>2,000$ & Competitive \\
Uridine & 699.0 & $>2,000$ & Competitive \\
5-Fluorouracil & $1,265.7$ & $>2,000$ & Competitive \\
Orotate & 770.9 & $>2,000$ & Competitive \\
5-Fluoroorotate & 165.9 & 132.0 & Competitive \\
Ribose 5-phosphate & 405.7 & $>2,000$ & Non-competitive
\end{tabular}

${ }^{*}$ All compounds were tested at concentrations of $125 \mu \mathrm{M}$.

\section{Discussion}

The PfOPRT-pQE30Xa and PfOMPDCpTrcHisA are co-transformed and co-expressed in E. coli. Both recombinant plasmids in the bacteria were retained stable at least 20 weeks. However, the PfOPRT-pQE30Xa plasmid stored for 16 and 20 weeks were decreased up to $8.3 \%$, indicating that PfOPRT-pQE30Xa plasmid was less stable than PfOMPDC-pTrcHisA plasmid in our E. coli clone.

The enzyme complex expressed in E. coli, are co-purified in sequential chromatographic steps according to the $\mathrm{Ni}^{2+}$-NTA agarose affinity, the Hi Trap Q HP anion-exchange and the Superose 12 gel-filtration FPLC columns. The molecular mass of PfOPRT-PfOMPDC enzyme complex is approximately $130 \mathrm{kDa}$, which was determined by Superose 12 gel-filtration FPLC column. The result of UMP-agarose affinity chromatography suggests that PfOPRT component and PfOMPDC component in the enzyme complex are tightly associated because of the PfOPRT component co-eluted with PfOMPDC component after $0.5 \mathrm{mM}$ UMP elution. This suggests that the conformation of the enzyme complex is relatively compact. This observation is consistent to the finding that the molecular mass of the enzyme complex is approximately $10 \mathrm{kDa}$ smaller than its expected size of $140 \mathrm{kDa}(20)$.

The product of OPRT, OMP, shows inhibitory effects to the PfOPRT component in the enzyme complex and the monofunctional form [18]. By contrast, $\mathrm{PPi}$, another product of OPRT, is a strong competitive inhibitor to the PfOPRT component in the enzyme complex [9], but has slightly inhibitory effect to the monofunctional enzyme. In addition, UMP, one of product of OMPDC, is the weak inhibitor to both enzyme forms. Our results implied that the products for each component of the enzyme complex are poor inhibitors, except for PPi that is the strong inhibitor for the PfOPRT in both forms [9]. Consequently, PPi may be a good candidate chemical for malarial therapy. The PfOPRT-PfOMPDC complex of the malarial parasite is possibly under a feedback inhibition. This phenomenon is similar to the properties of human and mouse bifunctional UMP synthase enzyme [14, 23], and so the PfOPRT-PfOMPDC enzyme might act as an allosteric protein. A more extensive kinetic analysis of the protein complex will provide further insights into the allosteric native of the $P$. falciparum enzymes. 
Taken together, the properties of the recombinant PfOPRT-PfOMPDC complex have authenticity to the native enzyme purified from $P$. falciparum culture [20].

Indeed, PfOPRT-PfOMPDC enzyme complex has many unique characters comparing the OPRT and OMPDC in any other organisms. The enzyme complex is the $\alpha_{2} \beta_{2}$ heterotetrameric protein $[17,20]$. In the PfOPRT component of the enzyme complex, there is 66 amino acid residues extension at the $\mathrm{N}$-terminus. On the other hand, the PfOMPDC component of the enzyme complex has 32 amino acid residues extension and 12 amino acid residues insertion between the peptides $[16-18,20]$. The enzyme complex has better in kinetic properties than both PfOPRT and PfOMPDC monofunctional forms [9]. These advantages may result from the extra amino acid residues of the PfOPRT and PfOMPDC component in the enzyme complex. However, it will not be clear until the crystal structure of the enzyme complex is elucidated [24].

Likewise, the PfOPRT-PfOMPDC enzyme complex has also an important character for malaria parasite to survive in the human host. Moreove, because of the benefits of kinetic properties, the complex has tolerated the higher temperature than those in their monofunctional forms [9]. However, the mechanism of complex formation in PfOPRTPfOMPDC enzyme complex remains unknown. It is postulated that the enzyme complex formation involves interaction of the extra amino acid residues of PfOPRT and PfOMPDC $[17,24]$. The enzyme-enzyme interactions are important targets for the design of novel therapy, especially targeting the interfaces between enzymes in the complex $[25,26]$.

In conclusion, the PfOPRT-pQE30Xa and PfOMPDC-pTrcHisA plasmids were co-transformed and co-expressed into E. coli. PfOPRT-PfOMPDC enzyme complex were co-eluted from both Superose 12 gel-filtration FPLC and UMP-agarose affinity columns. This enzyme complex has a unique characteristic and does not exist in human host cell. Thus, it is a potential drug target. A search for selective inhibitors to function as suitable drugs would enable a better control of malaria.

\section{Acknowledgement}

We thank Dr. S.R. Krungkrai for kindly providing PfOPRT-pQE30Xa and PfOMPDC-pTrcHisA plasmids. The study was supported by Thailand
Research Fund (to J.K.) and Chulalongkorn University Graduate School Thesis Grant (to P.K.). The authors have no conflict of interest to report.

\section{References}

1. Ridley RG. Medical need, scientific opportunity and the drive for antimalarial drugs. Nature. 2002; 415 : 686-93.

2. Breman JG, Alilio MS, Mills A. Conquering the intolerable burden of malaria: what's new, what's needed: a summary. Am J Trop Med Hyg. 2004; 71(2 Suppl):1-15.

3. Ndungu FM, Urban BC, Marsh K, Langhorne J. Regulation of immune response by Plasmodiuminfected red blood cells. Parasite Immunol. 2005; 27: 373-84.

4. Riley EM. Is T-cell priming required for initiation of pathology in malaria infections? Immunol Today. 1999; 20:228-33.

5. Dondorp AM, Nosten F, Yi P, Das D, Phyo AP, Tarning $\mathrm{J}$, et al. Artemisinin resistance in Plasmodium falciparum malaria. N Engl J Med. 2009; 361:455-67.

6. Htut ZW. Artemisinin resistance in Plasmodium falciparum malaria. N Engl J Med. 2009; 361:1807-8.

7. Stein WD, Sanchez CP, Lanzer M. Virulence and drug resistance in malaria parasites. Trends Parasitol. 2009; 25:441-3.

8. Krungkrai J, Krungkrai S. Malaria parasite: Genomics, biochemistry and drug target for antimalarial development. Chula Med J. 2006;50:127-42.

9. Kanchanaphum P, Krungkrai J. Kinetic benefits and thermal stability of orotate phosphoribosyltransferase and orotidine 5'-monophosphate decarboxylase enzyme complex in human malaria parasite Plasmodium falciparum. Biochem Biophys Res Commun. 2009; 390: $337-41$.

10. Umezu K, Amaya T, Yoshimoto A, Tomita K. Purification and properties of orotidine-5'-phosphate pyrophosphorylase and orotidine-5'-phosphate decarboxylase from baker's yeast. J Biochem. 1971; 70: 249-62.

11. Quinn CL, Stephenson BT, Switzer RL. Functional organization and nucleotide sequence of the Bacillus subtilis pyrimidine biosynthetic operon. J Biol Chem. 1991;266:9113-27.

12. Jones ME. Pyrimidine nucleotide biosynthesis in animals: genes, enzymes, and regulation of UMP biosynthesis. Annu Rev Biochem. 1980; 49:253-79.

13. Livingstone LR, Jones ME. The purification and preliminary characterization of UMP synthase from human placenta. J Biol Chem. 1987; 262:15726-33. 
14. Yablonski MJ, Pasek DA, Han BD, Jones ME, Traut TW. Intrinsic activity and stability of bifunctional human UMP synthase and its two separate catalytic domains, orotate phosphoribosyltransferase and orotidine-5'-phosphate decarboxylase. J Biol Chem. 1996;271:10704-8.

15. Gardner MJ, Hall N, Fung E, White O, Berriman M, Hyman RW, et al. Genome sequence of the human malaria parasite Plasmodium falciparum. Nature. 2002; 419:498-511.

16. Krungkrai J, Prapunwattana P, Wichitkul C, Reungprapavut S, Krungkrai SR, Horii T. Molecular biology and biochemistry of malarial parasite pyrimidine biosynthetic pathway. Southeast Asian J Trop Med Public Health. 2003; 34 (Suppl 2):32-44.

17. Krungkrai SR, DelFraino BJ, Smiley JA, Prapunwattana P, Mitamura T, Horii T, et al. A novel enzyme complex of orotate phosphoribosyltransferase and orotidine 5'-monophosphate decarboxylase in human malaria parasite Plasmodium falciparum:physical association, kinetics, and inhibition characterization. Biochemistry. 2005; 44:1643-52.

18. Krungkrai SR, Aoki S, Palacpac NM, Sato D, Mitamura $\mathrm{T}$, Krungkrai J, et al. Human malaria parasite orotate phosphoribosyltransferase: functional expression, characterization of kinetic reaction mechanism and inhibition profile. Mol Biochem Parasitol. 2004; 134 : 245-55.

19. Bradford MM. A rapid and sensitive method for the quantitation of microgram quantities of protein utilizing the principle of protein-dye binding. Anal Biochem. 1976; 72:248-54.
20. Krungkrai SR, Prapunwattana P, Horii T, Krungkrai J. Orotate phosphoribosyltransferase and orotidine 5'monophosphate decarboxylase exist as multienzyme complex in human malaria parasite Plasmodium falciparum. Biochem Biophys Res Commun. 2004; 318 : 1012-8.

21. Krungkrai J, Wutipraditkul N, Prapunwattana P, Krungkrai SR, Rochanakij S. A nonradioactive highperformance liquid chromatographic microassay for uridine 5'-monophosphate synthase, orotate phosphoribosyltransferase, and orotidine 5'monophosphate decarboxylase. Anal Biochem. 2001; 299:162-8.

22. Cleland WW. Statistical analysis of enzyme kinetic data. Methods Enzymol. 1979;63:103-38.

23. Floyd EE, Jones ME. Isolation and characterization of the orotidine 5'-monophosphate decarboxylase domain of the multifunctional protein uridine 5'-monophosphate synthase. J Biol Chem. 1985; 260: 9443-51.

24. Tokuoka K, Kusakari Y, Krungkrai SRM, Matsumura H, Kai Y, Krungkrai J, et al. Structural basis for the decarboxylation of orotidine 5'-monophosphate (OMP) by Plasmodium falciparum OMP decarboxylase. J Biochem. 2008; 143:69-78.

25. Fletcher S, Hamilton AD. Targeting protein-protein interactions by rational design: mimicry of protein surfaces. J R Soc Interface. 2006; 3:215-33.

26. Wells JA, McClendon CL. Reaching for high-hanging fruit in drug discovery at protein-protein interfaces. Nature. 2007; 450:1001-9. 